ALBERT H. RUBENSTEIN, DAVID J. WERNER, GUSTAVE RATH, JOHN A. KERNAGHAN, ROBERT D. O'KEEFE

\title{
Search Versus Experiment- the Role of the Research Librarian
}

Medical researchers, clinical specialists, and their supervisors covered by this survey, did not make frequent use of the services of research librarians, even after these services were specifically introduced to them. The potential value of a research librarian seems to depend upon the early education of the researcher and his awareness of the research librarian's professional capabilities.

\section{INTRODUCTION}

D ESPITE SUBSTANTIAL ADVANCES RECENTLY MADE in the indexing, abstracting, storing, and transmitting of scientific and technical information, many researchers continue to duplicate experiments rather than attempt to retrieve the needed information. They find that duplication is often less time-consuming and more certain in its results than is searching through various information channels with no guarantee of success. Yet, most researchers will also admit that although duplication often serves a real function, constant repetition of routine work wastes valuable resources and decreases real output.

New information systems aim to reduce this duplication by making retrieval the more attractive alternative. A multiplicity of highly specialized, mis-

The authors are associated with the Department of Industrial Engineering \& Management Sciences, The Technological Institute, Northwestern University, Evanston, Illinois. Work in this area has been supported at Northwestern since 1966 by the $\mathrm{Na}$ tional Library of Medicine, National Institutes of Health. sion-oriented services, however, do already exist in thousands of special libraries in universities, research institutes, and corporations. Often these services are by-passed by researchers either because they are ignorant of their availability or because they think services will be too slow and cumbersome.

While we experiment with new information retrieval systems, we should also inform researchers about current services and encourage their use. The services of research librarians, in particular, of medical librarians, best illustrate this issue.

\section{Methodology}

\section{Sites and Participants}

As the research was designed to study group reactions to the introduction of a new information service, only welldefined work groups were selected. Because specific organizational constraints and specific disciplines often affect information-seeking behavior, groups were chosen from several hospitals and from various disciplines as well as various orientations (clinical, research, or supervisory). (A "clinician," as used in this study, spends at least 75 percent of his time in patient care; a "researcher" 
spends at least 75 percent of his time in pure or applied biomedical research; and a "supervisor" administers either patient care or various research activities. ${ }^{\circ}$ )

In the Chicago area, the specialties of oncology and cardiology yielded a sample that satisfied the above criteria. Six hospitals were selected, with both an oncology and a cardiology group from each. Membership in the 12 groups initially numbered 110 . Eleven individuals were not able to participate beyond the first stage of the experiment. Of the 99 individuals who continued to participate, 71 held M.D.s, 11 held Ph.D.s, and 4 held both degrees. Five of the groups, three in cardiology and two in oncology, reported a high research orientation. Four groups reported a high clinical orientation (two in each discipline), and the remaining three groups reported a dual research-clinical orientation.

\section{Phases of the Field Experiment}

The research program was divided into three phases. (1) A detailed questionnaire was administered to each participant to gather data about his personal background, educational experience, organization environment, and present habits of information-seeking. (2) An experimental information retrieval system was introduced into each group's work environment, and the participant's reaction to it was carefully monitored. Each group had access to the system for seven weeks. The retrieval system linked participants with a remote "storehouse" of information-the John Crerar Library in Chicago-both by means of a

- The participants in this study performed four types of work: research, patient care, administration, and teaching. For the purposes of this study, the time each participant spent teaching his specialty was eliminated from consideration. Three categories were thus formed: researchers, clinicians, and supervisors. With teaching eliminated, no participant spent less than 75 percent of the remainder of the time working in his own area of specialization. telephone for placing requests and a facsimile system for the immediate transmission of requested material to the participant's place of work. A professional medical librarian was the focal point of the system. She received all requests for information and performed the necessary searches. (3) Six months after the service was discontinued, each participant was asked to evaluate the system, and his evaluation was compared with his actual use of the system.

\section{Results ANd Discussion}

\section{A Case History of Search Versus Experiment}

During the pilot study for the field experiment, an event occurred that put into sharp focus the relative merits of search versus experiment. ${ }^{1}$ A researcher, working in the basic research department of a major Chicago area hospital, reported that he intended to repeat an experiment because he did not think "it would be worth the time and the trouble" to attempt to retrieve the information he needed.

The information he needed was to answer the question: "Can substance $\mathrm{X}$ be successfully treated by process Y?" $\mathrm{He}$ knew that other less refined substances had been treated with this process, but he was not sure if exactly the same process would work with such a highly refined material as X. As he did not know where the information was readily available, he repeated the experiment. The experiment required four hours of a technician's time, spread over two days because of a required waiting period. The researcher spent approximately twenty minutes to explain the experiment to the technician. If Dr. B had chosen to retrieve the information, he would have had to perform the search himself, with little guarantee of success, because the data was not available in the sources he knew. He thus de- 
cided not to risk his time on what might have been a lengthy task.

A few days after Dr. B had made his decision, Mrs. A-a specially trained medical librarian-was assigned to work full-time in Dr. B's program. The librarian was given all the facts from Dr. B regarding his question, including information about the other applications of the process he wished to use. She was instructed to keep an accurate account of the time she spent and the sources she used in finding the information Dr. B needed. Her results are presented in Table 1.

The time taken by Mrs. A to find the necessary information was thirty-six minutes. She spent 70 percent of this time checking written sources that proved to be of no assistance. Because she happened to be at the Crerar $\mathrm{Li}$ brary when she received the request, she decided first to check the written sources. She indicated, however, that if she had had immediate access to a telephone at the outset of her search, she would have tried the verbal sources first. She was relatively sure that she could obtain the information through personal contacts. Had she initially used the verbal channel, it would have taken her only 11 minutes to retrieve the information for Dr. B. (The brevity of her search did hinge upon having a number of personal contacts, but that is not unusual. Part of a special librarian's job is to cultivate such sources of information.)

Although it did take Mrs. A thirty-six minutes to find the information, that was far less an investment of time than the four hours it took Dr. B and his technician to achieve the same results. Although Dr. B used only twenty minutes of his own personal time, had he been able to delegate the search to Mrs. A, it might have taken him less than half that time to explain to her what he needed. If the research librarian had been a familiar source for Dr. B, he probably would have considered a search the more attractive alternative than a repetition of the experiment. Searching would have been less costly and time consuming than duplication.

\section{Information-Seeking Patterns}

This case history is by no means unique. During the first phase of the

TABLE 1

Time and Results of the Librarian's Information Search

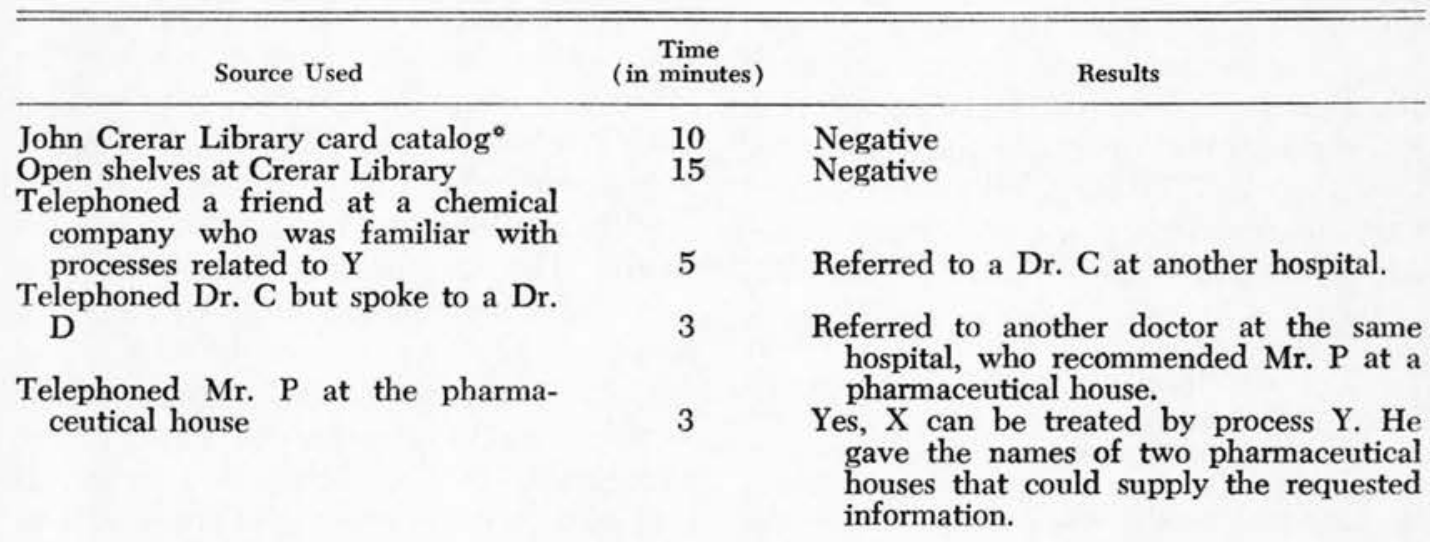

- The John Crerar Library is a privately supported public library located in Chicago and serving science, engineering, and medicine. Its collections contain over $1,000,000$ volumes. 
full field experiment, the participants were asked to (1) "indicate with a check mark how frequently you use each of the listed information sources" and (2) to report "what have been the main sources of influence in the development of the way in which you currently keep yourself informed." The results of the researchers' and clinicians' reported frequency of use of the listed information sources are presented in Table 2. Seventy percent of the researchers and 74 percent of the clinicians use the services of a librarian less than once a month.

In comparison with the general patterns that emerge from Table 2, the low utilization of the librarian is surprising for three reasons. First, since both groups make relatively frequent use of written sources and libraries, one would expect a comparably frequent use of librarians. However, this is not the case. Second, the researchers' use of written sources and libraries is significantly greater than that of the clinicians, one would expect an equally greater utilization of librarians. There is, however, no significant difference between the researchers and the clinicians in the frequency with which they use librarians. Third, although both groups reported a high verbal orientation-dependence on colleagues, subordinates, and supervisors for information, the librarian is utilized much less than other verbal sources of information, even though his value as a verbal source can often be greater (as our case history illustrated) than an individual's other personal contacts. It seems that an individual's use of a research librarian is not directly related to the frequency with which he uses a library; and that neither the researchers nor the clinicians regard the librarian as a valuable colleague.

This confidence gap between scientists and librarians has been noted by other studies. Slater and Fisher, during a study of the use made of technical libraries in Great Britain, observed that academic scientists were unwilling to delegate literature searches to the librarians in their respective universities. ${ }^{2}$ A 1969 re-

TABLE 2

Frequency of Source Use of Scientific and Technical Information

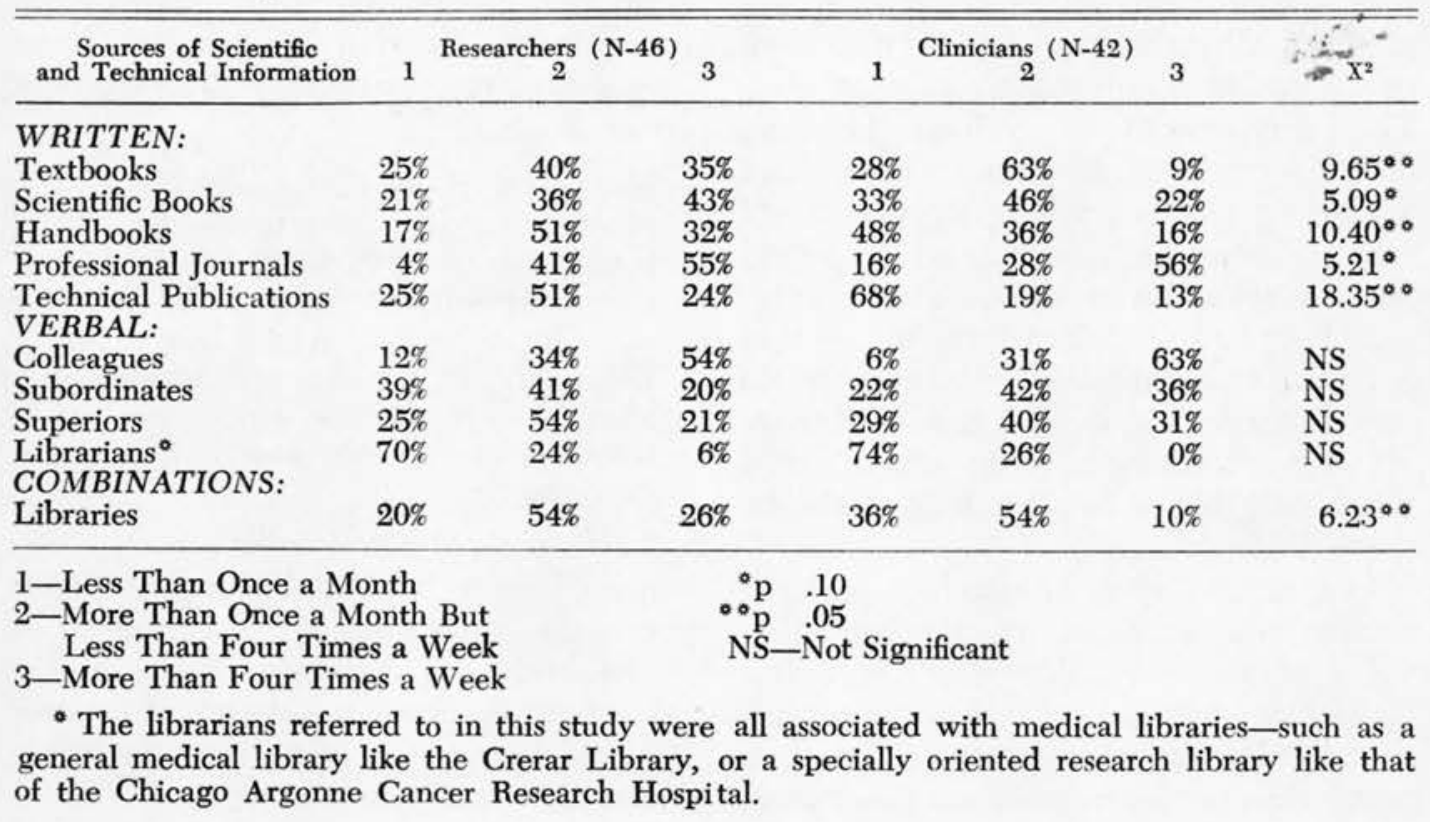


port from the British Office for Scientific and Technical Information revealed that, among a sample of students engaged in chemical research, more than 52 percent had never asked a member of the library staff for help in performing literature searches, while 39 percent asked for such help only on rare occasions. $^{3}$ Hall has observed that "despite their apparent academic status, librarians are seldom regarded as an equal by their colleagues in teaching and research." He outlines factors possibly accounting for this situation, which will be discussed later. ${ }^{4}$

Researchers in both pure and clinical sciences often lament the vast scattering of important information in books and journals, making it impossible to keep track of what is being published. If a researcher is unable to read a specific journal and asks a colleague for a description of what it contains, at best he will receive a summary description committed to an often faulty memory. A research librarian, on the other hand, has immediate access to all the written sources and should be able to provide a full and accurate account. Such a librarian can also regularly supply current tables of contents, bibliographies of new dissertations, and reprints of new articles according to subject area. The services of a trained librarian could be one of the researcher's most important means for keeping abreast of what is being published in his own field and in related specialties. If these researchers and clinicians were aware that a research librarian like Mrs. A could save them a great deal of time and money, the frequency with which they would use his or her services might be quite different.

One reason many researchers and clinicians are unaware of the potential value of a research librarian (and thus do not regard him or her as a professional colleague) can be traced to their past educational training in the use of information sources. ${ }^{5}$ When the participants in this experiment were asked to indicate which factors had been most influential in determining their present style of seeking information, only 13 percent of the researchers and 2 percent of the clinicians mentioned specific education in the use of information sources. (See Table 3.)

This lack of training can be accounted for, in part, by the lack of activity on the part of library directors and librarians. The results of a national survey of the user services offered by medical school libraries in the United States revealed that only twenty-one of the ninety-two libraries surveyed provided "formal" instruction (defined as required or elective courses) designed to help medical students and faculty make optimal use of information sources and services. ${ }^{6}$ The authors go on to comment that "at over half of these twentyone libraries, the courses rely solely on passive instructional methods-lectures, assigned readings, etc.-as contrasted to methods that require the active participation of students, such as small group seminars, practical exercises, etc." In most of the libraries that offer only "informal" instruction, such instruction usually consists of a one- or two-hour orientation tour or lecture. The authors conclude that:

instruction is an area where there is
great room for improvement. The
usual orientation tour or lecture ac-
complishes little that cannot be better
done by a good written guide to the
library and its services; and passive in-
structional modes are inadequate for
teaching the optimal use of informa-
tion resources.

Lack of financial resources or the absence of enough trained personnel, may prevent many libraries from offering detailed and on-going instruction in the use of information resources. However, if such instruction is to be offered, it seems that the library must be the focal 
point for training. Our own informal inspection of the courses offered by six major medical schools in the midwestern and western United States revealed that only one school listed a course in the use of information services, and that course concerned computer use for

TABLE 3

MOST IMPORTANT INFLUENCE IN FORMING Researchers' and Clinicians' InformationSEEkINg STYLe

\begin{tabular}{|c|c|c|}
\hline Influence & $\begin{array}{l}\text { Researchers } \\
(\mathrm{N}-46)\end{array}$ & $\underset{(\mathrm{N}-42)}{\text { Clinians }}$ \\
\hline \multirow{6}{*}{$\begin{array}{l}\text { Personal (colleagues) } \\
\text { Written Sources } \\
\text { General Education } \\
\text { Specific Education in the Use } \\
\text { of Information Services }\end{array}$} & $33 \%$ & $50 \%$ \\
\hline & $31 \%$ & $17 \%$ \\
\hline & $23 \%$ & $31 \%$ \\
\hline & & \\
\hline & $13 \%$ & $2 \%$ \\
\hline & $100 \%$ & $100 \%$ \\
\hline
\end{tabular}

the storage and retrieval of information. Although universities should be encouraged to offer more courses in the use of information sources and services, the responsibility for training students and faculty in the use of library services can only rest with the library staff itself.

\section{The Participant's Use of the}

Experimental Information System

During the second phase of the experiment, the participants were introduced to a new (to them) information retrieval system. A professional medical librarian was stationed at the John Crerar Library. The participants could request any type of information, ranging from requests for reprints of specific articles, literature searches, and answers to specific questions such as the one posed by Dr. B in our case history. They could request this information by phone or letter and once the search was performed, the information was sent to them immediately by means of a facsimile system connection between the library and each group's work area in the various hospitals. Each group had access to the system for seven weeks.
Of the ninety-nine individuals who were exposed to the new system (fortysix researchers, thirty-one clinicians, ${ }^{\circ}$ and twenty-two supervisors), forty individuals used the system to make a total of 141 requests. The percentage of use by each category is shown in Table 4 .

TABLE 4

Use of the New Information SeRvice by Each Category

\begin{tabular}{|c|c|c|}
\hline Category & $\begin{array}{c}\text { Users } \\
\text { (N-40) }\end{array}$ & $\begin{array}{l}\text { Nonusers } \\
\text { (N-59) }\end{array}$ \\
\hline Researchers (N-46) & $52 \%$ & $48 \%$ \\
\hline Supervisors (N-22) & $36 \%$ & $64 \%$ \\
\hline Clinicians (N-31) & $23 \%$ & $77 \%$ \\
\hline TOTAL (N-99) & $40 \%$ & $60 \%$ \\
\hline
\end{tabular}

The significance of a 40 percent use of the new information system is debatable. However, in our context, the most interesting part of the data concerns the type of requests made of the librarian stationed at the John Crerar Library. Of the 141 requests for information, 85 were for copies of specific articles, 50 requests were for either reprints of existing bibliographies or the compilation of new bibliographies in a given subject area, and only 6 requests were for literature searches or answers to specific questions. The behavior of the researchers and clinicians, in terms of the types of requests they made of the librarian, corroborate the previously discussed "confidence gap" between researchers and librarians.

\section{Conclusions}

Although great emphasis is currently on developing complex new systems for information retrieval, quite possibly a greater emphasis needs to be placed upon informing users about current information services, encouraging them to use these services, and making the ser-

\footnotetext{
$\because$ Eleven of the clinicians did not participate in this phase of the study.
} 
vices more responsive to their individual needs. Librarians can try to establish themselves as professional colleagues in the eyes of the researchers with whom they interact. As Hall observed, librarians must begin by "participating more actively in the affairs of the university and by insuring that they are always deployed on work which is commensurate with their abilities." This means that librarians should "advertise their expertise in information retrieval." $\mathrm{He}$ goes on to remark that one "way of breaking down the physical and psychological barriers between library and teaching staffs . . . is to establish a librarian/information officer" who will be directly responsible for one specific subject area and who will actively make contacts in each university department or research institute that deals with that subject area. Through this type of interaction, the teaching or research staff will learn that the librarian "has some knowledge of their subject area and will be free to concentrate on the practical benefits of such a service."

Although it is extremely difficult to alter the information-seeking style of mature researchers, the librarian can try to reach the younger researchers, the undergraduate and graduate students. The preliminary results from a planned fiveyear longitudinal study of how information-seeking style is formed among medical students in the United States indicates that these students are not welltrained in the use of information sources and do not take advantage of all the information resources available to them. ${ }^{8}$ If researchers could be trained in the efficient use of information systems and services, existing systems and services could function more effectively.

\section{REFERENCES}

1. David J. Werner, "A Study of the Relationships between Some Task, Professional, Personal, and Organizational Characteristics and the Use of an Experimentally Introduced Information System in a Medical Environment," a Ph.D. dissertation, Department of Industrial Engineering and Management Sciences, Northwestern University, Document Number 69/25, June 1969.

2. M. Slater and P. Fisher, "Use of Technical Libraries," ASLIB Occasional Publication no.2, London, 1969.

3. Office for Scientific and Technical Information, "Students Chemical Information Project," Final Report: Part 1, February 1969; Part 2, June 1969, London. Of course, in some universities, students are not encouraged to request help in actually doing a literature search, although they are generally encouraged to seek guidance in their search strategy.

4. J. Hall, "Information Services in University Libraries," ASLIB Proceedings, v.24, no.5 (May 1972), p.293-302.

5. Albert H. Rubenstein, "A Longitudinal Study of the Development of Information
Style," in Management Information Systems, ed. by Erwin Grochla. Wiesbaden: Betriebswirtschaftlicher Verlag, 1971.

6. Richard Orr, Harold Bloomquist, Gwendolyn S. Cruzat, and Arthur P. Schless, "User Services Offered by Medical School Libraries in 1968: Results of a National Survey," Bulletin of the Medical Library Association 58 , no.4 (Oct. 1970), p. 455-92.

7. J. Hall, "Information Services ... ," p.301.

8. Albert H. Rubenstein, "The National Institutes of Health Longitudinal Study Progress Report: The Development of Information Style by Researchers," Department of Industrial Engineering and Management Sciences, Northwestern University, Document Number 71/46, August 1971. See also, this author and Gustave J. Rath, Robert D. O’Keefe, John A. Kernaghan, Evelyn A. Moore, William C. Moor, David J. Werner, "Behavioral Factors Influencing the Adoption of an Experimental Information System by Medical Researchers and Clinicians in Six Hospitals," Catalog of Selected Documents in Psychology: 2:101-2 (Summer 1972). 